\title{
Towards Solar Pond Design and Development for Masdar City Environment
}

\author{
Khadije El Kadi, Isam Janajreh* \\ Mechanical and Materials Engineering Department, Khalifa University of Science and Technology, Masdar Institute, \\ Masdar City, P.O Box 54224, Abu Dhabi, United Arab Emirates
}

\begin{abstract}
Salinity-gradient solar ponds (SGSP) are water bodies that serves as a solar thermal energy storage system. Establishing a salinity gradient and observing the role of gravity and diffusion between the different zones is key-point in achieving optimal system performance. In this work, a numerical model is developed using computational fluid dynamics (CFD) acting as an initial step in designing and building a solar pond located in Masdar City for the usage of space cooling and desalination. The model is governed by continuity, species transport, momentum, and energy equations of naturally convicted, transient and non-isothermal flow. Results show the stability of the three working zones of the pond if carefully are injected and established. Although diffusion lingers for long time, it is balanced by the gravity forces that slows its propagation and confined it to a thin layer located at corresponding interfaces between zones. This work numerically shows the diffusion influence on the extent of stability of the three core zones of the solar pond. It demonstrates how one could achieve sustainable salinity and temperature gradients to ensure reliable working principle of the sola pond.
\end{abstract}

Keywords: Solar pond; Salinity gradient; CFD; SGSP; Solar thermal; Energy storage

\section{Introduction}

A solar pond has been recognized as an attractive renewable and cost-effective method for medium to large-scale solar thermal energy storage [1-2]. It consists of a staggering three-layered water body of different salinity water that accumulates and store solar radiation as sensible energy [3]. As illustrated in Fig. 1, a standard salinity gradient solar pond (SGSP) consists of three zones: (i) Upper Convective Zone (UCZ); (ii) Non-Convective Zone (NCZ); And (iii) Lower Convective Zone (LCZ). Salinity is lowest (i.e. fresh or seawater salinity 1800-35000 ppm) in the thin UCZ, whereas in the NCZ, salinity increases linearly by depth until reaching the saturation level (i.e. 200,000-390,000 ppm) in the LCZ [4]. NCZ is also known as the insulation zone (IZ) as it isolates the two other zones by suppressing its natural convection currents [5]. NCZ is the main contributor of solar pond performance, as it permits large proportion (up to $45 \%$ [6]) of solar radiation to infiltrate to the storage LCZ zone, it is also distinguished by its highest density brine. Water temperature reaches its highest and it range from $50^{\circ} \mathrm{C}$ to $90^{\circ} \mathrm{C}$ in the $\mathrm{LCZ}$. Therefore, the side and bottom walls that bound this zone may endure a substantial heat loss if not properly insulated [5]. To extract the accumulated low-grade thermal energy in the LCZ of the solar pond, a thermo-pipe network can be used as a heat exchanger. This can be facilitated by flowing a heat transfer fluid (HTF) inside the pipes of the heat exchanger to extract the thermal heat from the LCZ. Therefore, SGSP has the capability of collecting solar energy with providing a long-term thermal energy storage. It can be used as a powerful cost-effective and reliable heat source in several applications such as low-energy desalination technologies (i.e. membrane distillation (MD) [7-8]), absorption chiller, and greenhouse heating, and/or pre-heating processes in power plants [6].

Abundant of research work using pilot-scale implementations and numerical models of SGSP have been spotted in literature [2,5,9-18]. Early in 1997, Badran et al. [2] have performed a 1-D numerical modeling of a SGSP and reported a constant heat supply throughout the year. Karakilicik

${ }^{*}$ Corresponding author.

E-mail: ijanajreh@masdar.ac.ae

(C) 2018 International Association for Sharing Knowledge and Sustainability

DOI: $10.5383 /$ ijtee. 16.01 .008 
et al. [5] have investigated the thermal performance of a pilotscale SGSP, thermal efficiency of $28.1 \%$ was recorded for the LCZ (i.e. storage zone). Recently, Valderrama et al. [9] have constructed a pilot plant solar pond in Spain with $50 \mathrm{~m}^{2}$ surface area and 3-m depth, salinity gradient was established by feeding salt to the bottom wall of the solar pond through a cylindrical charger. The solar pond has shown a stable performance through a year and reported a maximum temperature of $55^{\circ} \mathrm{C}$ [9]. In other work of the same authors, performance of the constructed solar pond was validated numerically recording a maximum temperature of $75^{\circ} \mathrm{C}$ which corresponds to $16 \%$ extraction of incoming solar radiation [10]. Torkmahalleh et al. [11] have also examined the performance of a model-scale solar pond of $0.6 \mathrm{~m}$ diameter and $0.55 \mathrm{~m}$ height located in Cyprus. A temperature of $48^{\circ} \mathrm{C}$ was recorded, however, this small scale shows high dependency on the ambient temperatures. The study also showed the exigency of having both surface washing of the UCZ and saturated brine at the LCZ for a better performance.

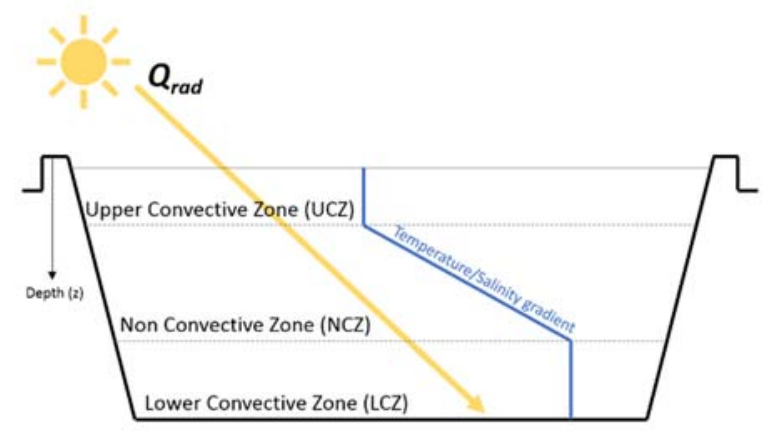

Fig. 1. Schematic of a typical solar pond showing its different zones along with their corresponding temperature and salinity gradients

Moreover, various numerical studies of molecular and thermal diffusion within the SGSP has been done. Suárez et al. [12] have numerically studied the effect of double-diffusive convection on the thermal performance and the stability of internal interfaces between the SGSP using finite volume method (FVM) in 2-D transient model. They found that the presence of constant motion at the internal interfaces between the zones can results into a loss of the non-convective zone [12]. Similar conclusion was reached by Boudhiaf and Baccar [13] using 1D transient regime. They have also found that at a constant time, higher temperatures of the UCZ and LCZ was recorded at higher Rayleigh number, i.e. when the heat from the convection of the fluid is higher than the one due to conduction [13]. Angeli et al. [14] have also solved the diffusion equation of salt and temperature within the solar pond. Their results show a non-negligible but smaller contribution of thermal diffusion when compared to the molecular one. Giestas et al. [15-16] have also developed a temperature- and salinity- dependent SGSP 2$\mathrm{D}$ transient model using justified weak formulations. The model was experimentally tuned and was used to predict several features of the SGSP dynamics. Whilst the above cited literature demonstrates the working principle of solar pond, it lacks the rigor and in-depth treatment and analysis of temporal development the diffusion layers, brine concentration gradient and their high-resolution temperature distribution. This information if obtained experimentally is limited to low resolution both specially and temporally. This work fills this literature gap by conducting a detailed multiple species CFD analysis under accurate binary diffusion at high resolution that capture the temporal extent of the diffusion for the three solar pond layers.
It should be noted there are multiple challenges of solar pond. These are climate change and seepage of brine through the ground adding to surrounding soil pollution. Therefore, usage of chemically stable of low permeability lining is necessary. Economic challenges include the availability, stability, and high cost brine formulation [1-2,17]. Although commercially available sodium chloride salt is appropriate for making artificial brine [6], the reuse of rejected brine from desalination plant (RO, Flashing, MD etc.) is stimulating further interest in solar pond deployment to reduce the environmental impact of the brine [18].

Abu Dhabi direct normal irradiance (DNI) is around 1,800 $\mathrm{kWh} / \mathrm{m}^{2}$ [19] which is a favorable condition for solar pond deployments. Such high radiation amount compared to other countries would strongly increase the LCZ temperature and its potential thermal energy. Moreover, because Abu Dhabi is characterized as low-wind region, a low induced surface mixing is expected. These two local favorable conditions are translated in an increase in the overall solar pond efficiency and economic feasibility. Nevertheless, surface evaporation due to high summer temperatures poses some problem, but this can be overcome by either replenishing the evaporated fresh water by integrating a simple make-up water system or by reducing the evaporation by mean of using optically transparent and floating covering. In this work present the development and analysis of numerical computational fluid dynamics (CFD) model of multispecies non-isothermal of salinity gradient solar pond (SGSP). It studies the effect of diffusion on the pond's stability aiming to achieve a reliable salinity and temperature gradients. This work acts as an initial step of solar pond design in the golf states such as Abu Dhabi and specifically for Masdar City's environment.

\section{Theory and System Setup}

In this work, numerical study of multi-species will be performed on a $1-\mathrm{m}$ radius solar pond (surface area of $3.14 \mathrm{~m}^{2}$ ) and $0.5 \mathrm{~m}$ total depth $(\mathrm{UCZ}=0.1 \mathrm{~m}, \mathrm{NCZ}=0.3 \mathrm{~m}, \mathrm{LCZ}=0.1 \mathrm{~m})$ with $90^{\circ}$ vertical side walls. The computational domain consists of multi-species fluid ( $\mathrm{NaCl}-\mathrm{H}_{2} \mathrm{O}$ mixture) with three different salinities $(0 \%, 10 \%$, and $25 \%)$ and eventually is subjected to temperatures from the top and bottom surfaces to simulate solar radiation effect. An axisymmetric segment of the geometry is shown in Figure 2 and presents the computational domain taking advantages of the cylindrical geometry. As can be seen in Figure 2 , the left-hand side simulates the symmetrical central axis for the cylindrical pond while the left-hand side is considered an adiabatic wall with no flow penetration of slip. Figure 2 illustrates the fluid domain and its corresponding boundary conditions.

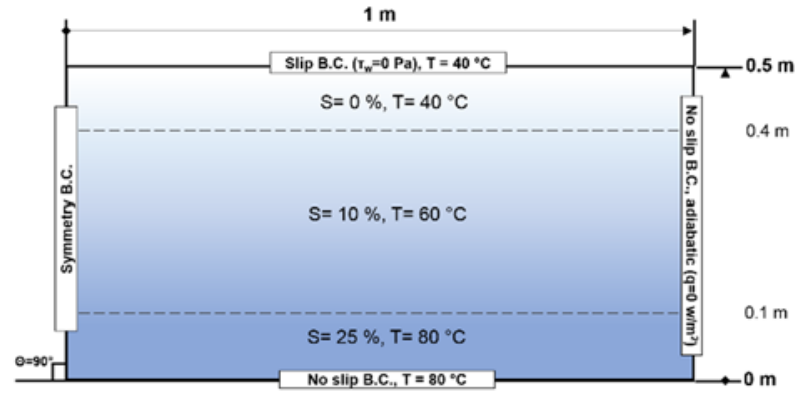

Fig. 2. Simplified salinity-temperature gradient domain with the assigned wall boundary conditions 
The numerical system is governed by the time dependent conservative laws of the continuity, the species transport, momentum (i.e. Navier-Stokes), and energy for the nonisothermal system. These equations are given by $[12,20]$ and are written as:

Mass conservation:

$\frac{\partial \rho}{\partial t}+\nabla \cdot(\rho \vec{V})=0$

Species transport:

$$
\frac{\partial}{\partial t}\left(\rho Y_{S}\right)+\nabla \cdot\left(\rho \vec{V} Y_{S}\right)=\nabla \cdot\left(\rho D_{s} \nabla Y_{S}\right)
$$

Momentum:

$\frac{\partial \rho \vec{V}}{\partial t}+\nabla \cdot(\rho \vec{V} \vec{V})=-\nabla \mathrm{P}+\mu \nabla^{2} \vec{V}+\rho \vec{g}$

Energy:

$$
\rho C_{p} \frac{D T}{D t}=\nabla \cdot(\mathrm{k} \Delta \mathrm{T})+\beta_{T} \mathrm{~T} \frac{D P}{D t}+\Phi_{h}
$$

where $\rho$ is the mixture density $\left(\mathrm{kg} / \mathrm{m}^{3}\right), t$ is time (s), $\vec{V}$ is the velocity field $(\mathrm{m} / \mathrm{s}), Y_{S}$ is the mass fraction of salt, $D_{S}$ is the solute (i.e. $\mathrm{NaCl}$ salt) diffusivity $\left(\mathrm{m}^{2} / \mathrm{s}\right), \mathrm{P}$ is pressure $(\mathrm{Pa}), \mu$ is the dynamic viscosity $\left((\mathrm{N} . \mathrm{s}) / \mathrm{m}^{2}\right), \vec{g}$ is the gravitational acceleration $\left(\mathrm{m} / \mathrm{s}^{2}\right), C_{p}$ is the specific heat capacity $(\mathrm{J} / \mathrm{kg} . \mathrm{K}), \mathrm{T}$ is temperature $(\mathrm{K}), \mathrm{k}$ is thermal conductivity $(\mathrm{W} / \mathrm{m} . \mathrm{K}), \beta_{T}$ is the thermal expansion coefficient $(1 / \mathrm{K})$, and $\Phi_{h}$ is the rate of internal thermal generation $\left(\mathrm{W} / \mathrm{m}^{3}\right)$.

Non-isothermal flow consists of the three species. The role of diffusion and gravity forces is studied to gain better understanding of its variation on the system performance. The model is also carried out to simulate the establishment of both salinity and temperature gradients and verify their stability with time in the presence of mass and thermal diffusion. The system of equations will be solved through the commercial CFD code FLUENT that is based on finite volume method (FVM) with a segregated solver. Using first order time implicit for time derivative and centralized $2^{\text {nd }}$ order for spatial derivative. The time step also is kept within the bounded stability criterial for accurate and progressive evaluation of the flow field and limited to Courant Friedrich Levy (CFL) of 10. This work aims at to optimize the operation of solar ponds by testing practical variations, while also gaining a reliable understanding of the inherited fluid dynamic phenomena such as diffusion and eventually thermal convection.

Diffusion flux is driven by the difference in the chemical species concentration and described by Fick's law as:

$J_{i}=-\rho D_{i, m} \nabla Y_{i}-D_{i, T} \frac{\nabla T}{T}$

where $D_{i, m}$ and $D_{i, T}$ are the mass and thermal diffusion coefficients for species $i$ in the multispecies mixture, respectively. If isothermal flow is considered, the $2^{\text {nd }}$ left term of equation relaxes (5). Fick's law diffusion approximation is valid for fixed mixture composition which is the case of saline water. Turbulence diffusion overwhelms the laminar counterpart. The diffusion coefficient has been looked at as a fixed fluid property value [1]. Considering the case of three fluids with different densities (specific weight) with the denser fluid at the bottom of a less dense fluid the gravity would work to keep the stability of the system. The fluid however tends to diffuse and go through a transient state motion. These results will be revealed in numerical simulation of the high fidelity unsteady Navier-Stokes simulation following the authors work [2-4].

These simulations are carried out using the 2-D unsteady non-isothermal Navier-Stokes equations of three species representing the three zones of the solar pond. Their distribution is solved in adiabatic wall bounded domain (side wall and bottom) of $1 \mathrm{~m}$ radius by $0.5-\mathrm{m}$ depth as depicted in Figure 2. In the first setup a thin layer $(0.1 \mathrm{~m})$ of the fresh water of $0 \%$ salinity $\left(\rho=1000 \mathrm{~kg} / \mathrm{m}^{3}, C p=4182 \mathrm{~J} / \mathrm{kg} . \mathrm{K}, \mathrm{k}=0.6 \mathrm{~W} / \mathrm{m} . \mathrm{K}, \mu=0.001\right.$ $\mathrm{kg} / \mathrm{m} . \mathrm{s}$ ) is placed at the top of mid salinity solution (i.e. $\mathrm{S}=10 \%$, $\rho=1100 \mathrm{~kg} / \mathrm{m}^{3}, C p=4100 \mathrm{~J} / \mathrm{kg} . \mathrm{K}, \mathrm{k}=0.59 \mathrm{~W} / \mathrm{m} . \mathrm{K}, \mu=0.0015$ $\mathrm{kg} / \mathrm{m} . \mathrm{s}$ ) on the top of high salinity solution (i.e. $\mathrm{S}=25 \%, \rho=1251$ $\left.\mathrm{kg} / \mathrm{m}^{3}, C p=4000 \mathrm{~J} / \mathrm{kg} . \mathrm{K}, \mathrm{k}=0.58 \mathrm{~W} / \mathrm{m} . \mathrm{K}, \mu=0.0015 \mathrm{~kg} / \mathrm{m} . \mathrm{s}\right)$ as initial conditions [21-23]. Mass diffusivity of the multi-species mixture in this study is kept constant at $2.32 \mathrm{e}-09 \mathrm{~m}^{2} / \mathrm{s}$ as reported for the brine liquid elsewhere in the literature. The computation is proceeded at small time step $(0.1 \mathrm{sec})$ to satisfies the stability criterion of Currant-Friedrichs Lewy (CFL) and enabling accurate capture of flow unsteadiness. A quadrilateral structured finite volume mesh (see Figure 3 ) is used for domain discretization of 360x64 that clustered next the bottom, top, and interfacial lines to physically resolve the developed boundary/mixing layer and capture the high velocity, temperature, and concentration gradients. The governing system of equation (mass, momentums, energy and species) are solved using Fluent ANSYS commercial code which is based on finite volume method (FVM). The differential equations are integrated over the finite volume of the computational cell and over a finite time where a second-order central difference scheme is used in the discretization of the convective and diffusive terms while first order fully implicit scheme used for time. The time iterative Semi Implicit Method for Pressure-Linked Equations (SIMPLE) solver scheme is adapted for the pressure-velocity coupling. A tight residual of 1e-6, for each of these equations is imposed.

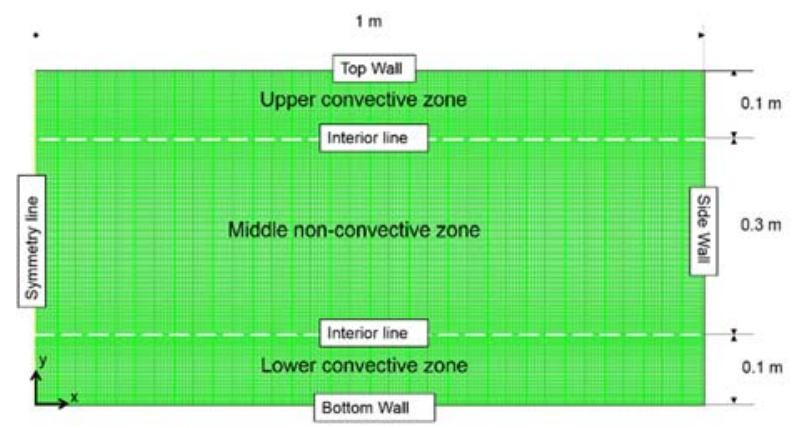

Fig. 3. SGSP numerical model setup and discretization mesh

\section{Results and Discussion}

In the current analysis, the previously characterized three water species are patched each in its corresponding zone at zero time as per Figure 3. The top layer of fresh water representing the UCZ is initiated with $0 \%$-salinity species at $40^{\circ} \mathrm{C}$. The NCZ is also patched with $10 \%$-salinity species at $60^{\circ} \mathrm{C}$ whereas the heavy brine LCZ is patched with $25 \%$-salinity species at $80^{\circ} \mathrm{C}$. The simulation is carried out for physical time of eight hours and the velocity field magnitude is illustrated in Figure 4. As expected the flow velocity is driven by the diffusion and concentration gradient. It was relatively high at the diffusion interfaces between the three zones. Moreover, velocity contours 
show clearly the existence of convective currents of the upper and lower convective zones (i.e. UCZ and LCZ) due to the constant temperature across them, whereas no or relatively very low currents are presence at the non-convective zone (NCZ). These illustrations bring more insight to the SGSP as they show the presence of localized eddies within the UCZ and LCZ that suggesting their name compared to none existence of any in the NCZ. Furthermore, it illustrates also the sustainability of these zones as time elapsed.

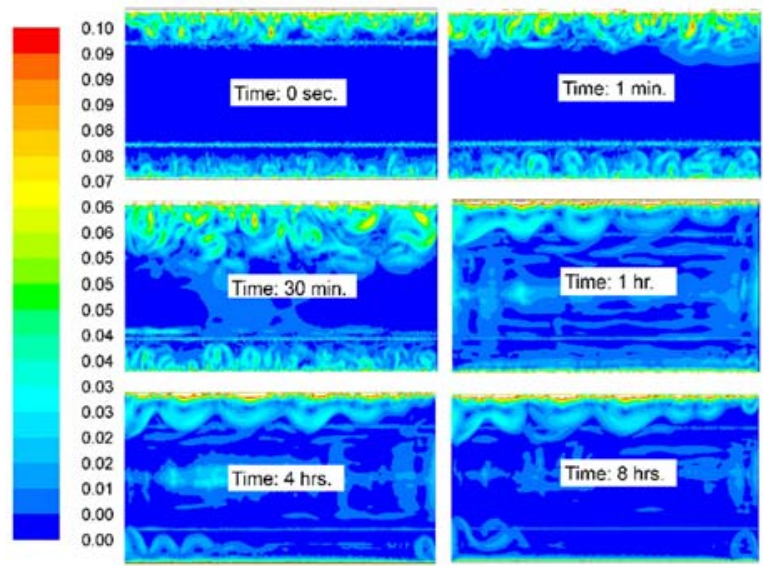

Fig. 4. Contours of velocity magnitude $(\mathrm{m} / \mathrm{s})$ of SGSP model at different flow times

Moreover, Figure 5 show contours of density across the SGSP at different flow times where the density is the best representation of species distribution and their diffusion through the three zones. Diffusion between the three species increases with time, however, higher diffusion between the $25 \%$-salinity solution and the $10 \%$-salinity solution is noticed than that between the $10 \%$-salinity solution and fresh $/ 0 \%$ salinity water. More precisely, Figure 6 illustrates the density distribution along the y-direction (i.e. solar pond depth) as time evolved starting from 10 seconds to 8 hours of operation. Although diffusion occurs at the three zones, after 8 hours of operation a stable density gradient was established and is due to gravity effect. As a result, salinity gradient of the non-convective zone starting at $0.125 \mathrm{~m}$ and ends at depth of $0.35 \mathrm{~m}$ was formed successfully.
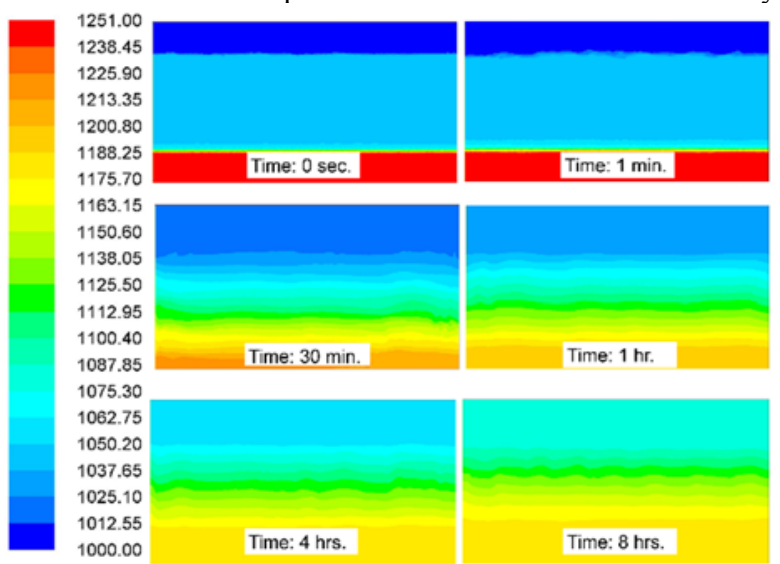

Fig. 5. Contours of density $\left(\mathrm{kg} / \mathrm{m}^{3}\right)$ of SGSP model at different flow times

Furthermore, the development of temperature gradient with time is clearly depicted in temperature contours and temperature distribution shown in Figures 7 and 8, respectively. Like density, a steady temperature gradient was obtained starting from depth of $0.125 \mathrm{~m}$ and ending at $0.35 \mathrm{~m}$ after 8 hours of operation (see Figure 8). Also, lower and upper convective zones were stabilized at a fixed temperature of $42^{\circ} \mathrm{C}$ and $79^{\circ} \mathrm{C}$, respectively.

As depicted in Figure 9, the resulting salinity and temperature gradient of the modeled solar pond were developed successfully. Salinity was obtained from mass fraction of the three-different species at each zone. The evolved LCZ of $0.15 \mathrm{~m}$ thickness has an average brine salinity of $\sim 19.7 \%$ and a constant average temperature of $78.9^{\circ} \mathrm{C}$, whereas the $\mathrm{UCZ}$ of $0.125 \mathrm{~m}$ thickness has shown a large rise in salinity that reaches an average value of $11 \%$ (UCZ was initiated at $\mathrm{S}=0 \%$ ) with a constant average temperature of $\sim 42^{\circ} \mathrm{C}$. On the other hand, $\mathrm{NCZ}$ has achieved a linear salinity and temperature gradients from $0.125 \mathrm{~m}$ depth to $0.35 \mathrm{-m}$ resulting in a total zone thickness of $0.225 \mathrm{~m}$.

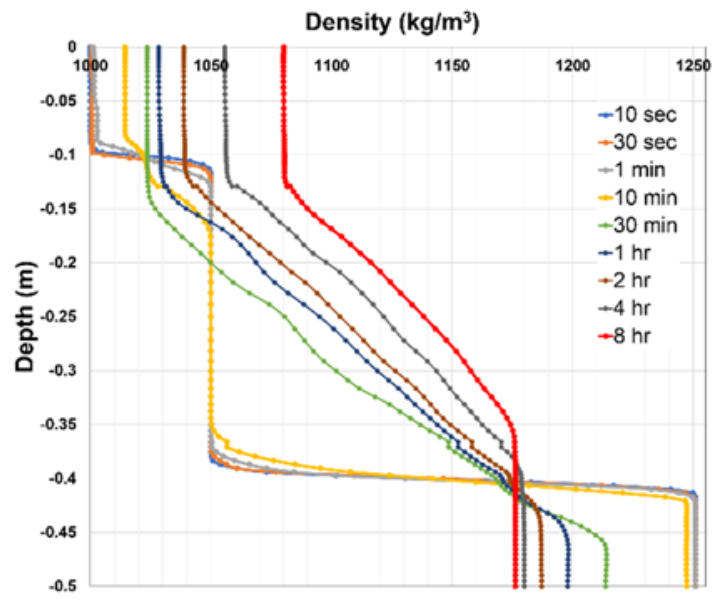

Fig. 6. Density distribution across the SGSP depth at different flow times (data recorded along midline $(x=0.5 \mathrm{~m})$ )

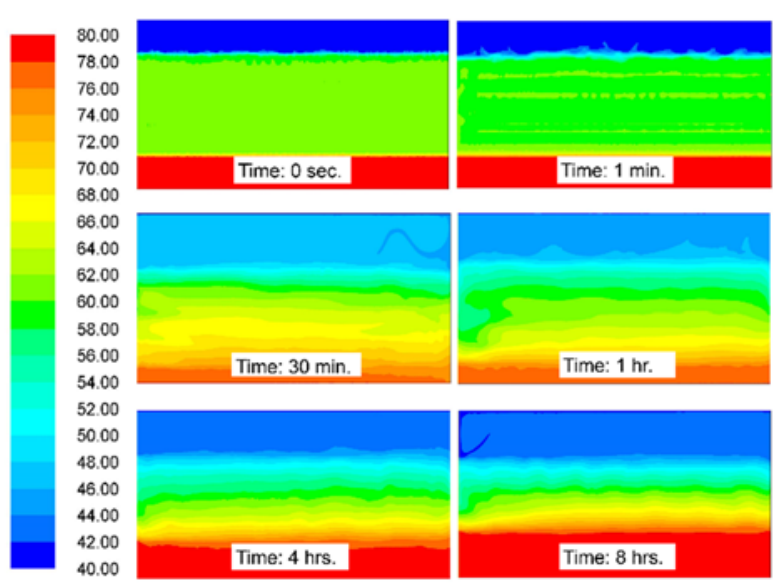

Fig. 7. Contours of temperature $\left({ }^{\circ} \mathrm{C}\right)$ of SGSP model at different flow times

\section{Conclusion}

In this work, multispecies non-isothermal transient computational fluid dynamic (CFD) model of salinity gradient solar pond (SGSP) was developed as a first step in designing and building a solar pond based in Masdar City. The model studied the effect of mass and thermal diffusion on the development of salinity and temperature gradients in the presence of gravity, it 
also studied the stability of internal interfaces between the SGSP zones. Results showed the existence of the convective zones (i.e. $\mathrm{UCZ}$ and LCZ) as well as the storage zone (i.e. NCZ) that consists of a stable salinity gradient in the range of $11 \%$ to $20 \%$ salt content. A temperature gradient ranges between $42^{\circ} \mathrm{C}$ and $79^{\circ} \mathrm{C}$ has been also developed in the $\mathrm{NCZ}$ whereas temperature and salt content were fixed at the convective zones. The developed model was generic to adapt different fluid salinity, zone depth, and temperatures, and hence is capable to simulate the SGSP performance under any condition. Further development of the numerical model to directly assess solar flux is recommended. Moreover, experimental setup of a SGSP will be also a valuable addition to validate the model.

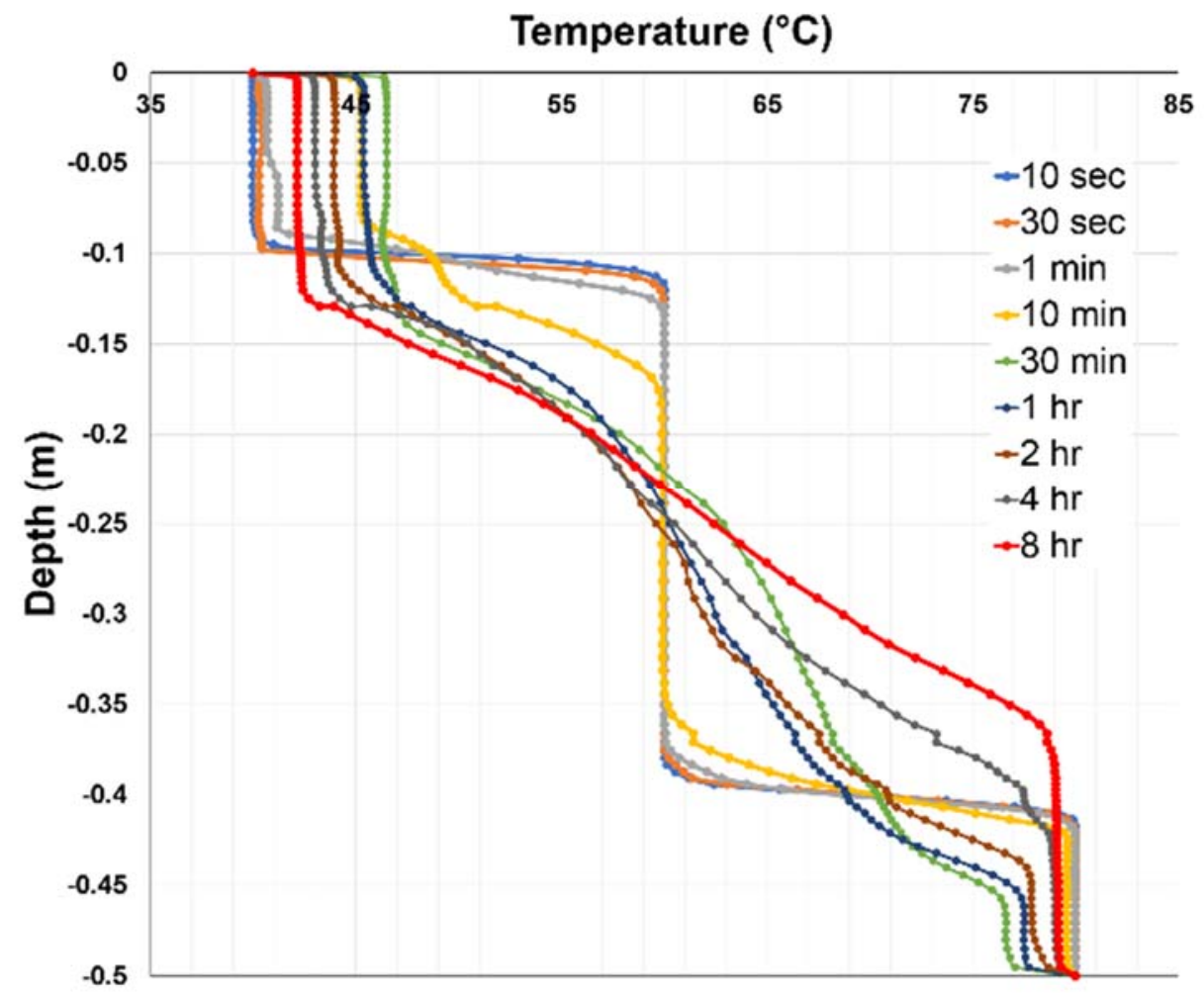

Fig. 8. Temperature distribution across the SGSP depth at different flow times (data recorded along midline $(\mathrm{x}=0.5 \mathrm{~m}))$

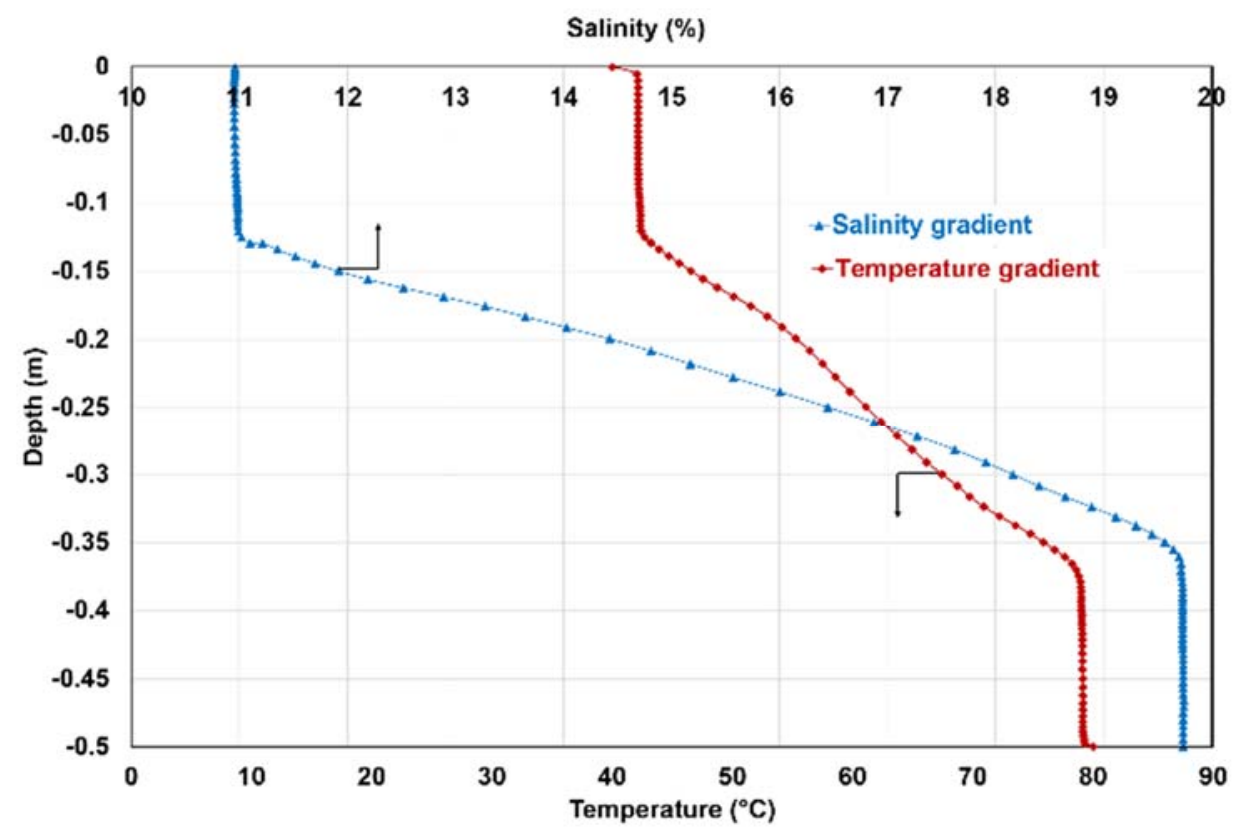

Fig. 9. Resulting temperature and salinity gradient of SGSP at flow time of 8 hours 


\section{References}

[1] B.A. Jubran, A.R. El-Baz, M.A. Hamdan, A.A. Badran, "Experimental Investigation of Local Clays and Clay Schemes as Liners for Solar Ponds," Int. J. of Energy Research, vol.20, pp. 637-642, 1996.

[2] A.A. Badran, B.A. Jubran, E.M. Qasem, M.A. Hamdan, "Numerical Model for the Behaviour of a Salt-Gradient Solar-Pond Greenhouse-Heating System," Applied Energy, vol.58, no.1, pp. 57-72, 1997.

[3] F. Suárez, J.A. Ruskowitz, S.W. Tyler, A.E. Childress, "Renewable water: Direct contact membrane distillation coupled with solar ponds," Applied Energy, vol.158, pp.532-539, 2015.

[4] K. Rahaoui, L.C. Ding, L.P. Tan, W. Mediouri, F. Mahmoudi, K. Nakoa, A. Akbarzadeh, "Sustainable membrane distillation coupled with solar pond," Energy Procedia, vol.110, pp. 414-419, 2017.

[5] M. Karakilcik, I. Dincer, M.A. Rosen, "Performance investigation of a solar pond," Applied Thermal Engineering, vol.26, pp.727-735, 2006.

[6] V. Velmurugan, K. Srithar, "Prospects and scopes of solar pond: A detailed review," Renewable and Sustainable Energy Reviews, vol.12, pp. 2253-2263, 2008.

[7] I. Janajreh, D. Suwwan, R. Hashaikeh, "Assessment of direct contact membrane distillation under different configurations, velocities, and membrane properties," Applied Energy, vol. 185, pp. 2058-2073, 2017.

[8] I. Janajreh, D. Suwwan, H. Faith, "Flow analysis of low energy direct contact membrane desalination," Int. J. Therm. Env. Eng., vol. 8, no. 2, 133-138, 2014.

[9] C. Valderrama, O. Gibert, J. Arcal, P. Solano, A. Akbarzadeh, E. Larrotcha, J. L. Cortina, "Solar energy storage by salinity gradient solar pond: Pilot plant construction and gradient control," Desalination, vol 279, pp. 446-450, 2011.

[10] F. Bernad, S. Casas, O. Gibert, A. Akbarzadeh, J. L. Cortina, C. Valderrama, "Salinity gradient solar pond: Validation and simulation model," Solar Energy, vol. 98, pp. 366-374, 2013

[11] M. A. Torkmahalleh, M. Askari, S. Gorjinezhad, D. Eroglu, M. Obaidullah, A. R. Habib, S. Godelek, S. Kadyrov, O. Kahraman, N. Z. Pakzad, G. Ahmadi, "Key factors impacting performance of a salinity gradient solar pond exposed to Mediterranean climate," Solar Energy, vol.142, pp. 321-329, 2017.

[12] F. Suárez, S.W. Tyler, A.E. Childress, "A fully coupled, transient double-diffusive convective model for salt-gradient solar ponds," Int. J. of Heat and Mass Transfer, vol.53, pp. 1718-1730, 2010.

[13] R. Boudhiaf, M. Baccar, "Transient hydrodynamic, heat and mass transfer in a salinity gradient solar pond: A numerical study," Energy Conversion and Management, vol. 79, pp. 568-580, 2014.

[14] C. Angeli, E. Leonardi, L. Maciocco, “A computational study of salt diffusion and heat extraction in solar pond plants," Solar Energy, vol. 80, pp. 1498-1508, 2006.

[15] M.C. Giestas, H. L. Pina, J. P. Milhazes, C. Tavares, "Solar pond modeling with density and viscosity dependent on temperature and salinity," Int. J. of Heat and Mass Transfer, vol.52, pp.2849-2857, 2009.

[16] M.C. GiestasJ. P. Milhazes, , H. L. Pina, "Numerical Modeling of Solar Ponds," Energy Procedia, vol. 57, pp. 2416-25, 2014.

[17] B.A. Jubran, A.R. El-Baz, M.A. Hamdan, A.A. Badran, "Effects of climate conditions of the performance of carnallite solar ponds," Int. J. of Ener. Res., vol.20, pp. 1037-1048, 1996.

[18] M. Hassairi, M.J. Safi, S. Chibani, "Natural brine solar pond: An experimental study," Solar Energy, vol.70, no.1, pp. 45-50, 2001.

[19] UAE Solar Atlas, Research Center for Renewable Energy Mapping and Assessment (RCREMA): A Masdar Institute Research Center, 2016, web: https://atlas.masdar.ac.ae/.

[20] A. Bejan, Convection Heat Transfer, third Ed., John Wiley \& Sons, New Jersey, 2004 [Chapters 1, 6 and 11].

[21] M. H. Sharqawy, J. H. Lienhard, and S. M. Zubair, "Thermophysical properties of seawater: A review of existing correlations and data," Desalination and Water Treatment, Vol. 16, pp.354-380, 2010.

[22] K.G. Nayar, M.H. Sharqawy, L.D. Banchik, and J.H. Lienhard V, "Thermophysical properties of seawater: A review and new correlations that include pressure dependence," Desalination, Vol. 390, pp.1-24, 2016.

[23] G.L. Dittman, "Calculation of brine properties," Lawrence Livermore Laboratory, U.S. Ener. Res. \& Dev. Admin., Feb. 1977. 